\title{
How to Disinfect Water After a Disaster
}

After a natural disaster, it is often the case that the water is not suitable for consumption. Please check with your local authorities to find out whether your water is safe.

If you do not have access to bottled water, there are two simple options to disinfect your water:

1. Boil the water for 1 minute

- If the water is cloudy, allow it to settle and then filter it with a clean cloth, paper towel or coffee filter.

- Boil the water for at least 1 minute (begin to count after the water reaches a rolling boil).

- Wait for the water to cool before consuming or storing.

\section{Disinfect the water with household chlorine bleach}

- If the water is cloudy, allow it to settle and then filter it with a clean cloth, paper towel or coffee filter.

- Use liquid household chlorine bleach (make sure that it is unscented) in the proper proportions indicated in the table below.

- Mix the water and bleach well and make sure to wait at least 30 minutes before use.

- The water should have a slight odor of chlorine bleach. If it doesn't, repeat the chlorine application and let it sit for another 15 minutes before use.

\begin{tabular}{|l|ll|}
\hline Volume of water & \multicolumn{1}{l|}{$\begin{array}{l}\text { Concentration of } \\
\text { chlorine bleach } 6 \%\end{array}$} & $\begin{array}{l}\text { Concentration of } \\
\text { chlorine bleach } \\
8.25 \%\end{array}$ \\
\hline 1 liter & 2 drops & 2 drops \\
1 gallon & 8 drops & 6 drops \\
2 gallons & 16 drops ( ${ }^{1}{ }_{4}$ teaspoon) & 12 drops ( ${ }^{1}{ }_{8}$ teaspoon) \\
4 gallons & $1_{3}$ teaspoon & $1_{4}$ teaspoon \\
8 gallons & ${ }_{2}$ teaspoon & $1_{2}$ teaspoon \\
\hline
\end{tabular}

\section{Warning!}

Fruits and vegetables must be washed with boiled or disinfected water.

Use no more than 1 teaspoon of chlorine per gallon of water. 
Water that is not suitable for consumption should not be used for cooking, washing dishes, brushing teeth or making ice cubes. Check the table below to determine which uses are safe according to each water supply source.

\section{Water supply source}

\begin{tabular}{ccccc}
\hline $\begin{array}{c}\text { Untreated } \\
\text { rainwater }\end{array}$ & $\begin{array}{c}\text { Treated } \\
\text { rainwater }\end{array}$ & $\begin{array}{c}\text { Surface } \\
\text { water (rivers, } \\
\text { streams, creeks) }\end{array}$ & $\begin{array}{c}\text { Groundwater } \\
\text { (untreated well } \\
\text { water, not AAA) }\end{array}$ & $\begin{array}{c}\text { Filtered, } \\
\text { chlorinated, } \\
\text { boiled or } \\
\text { bottled } \\
\text { water }\end{array}$ \\
X & $\checkmark$ & X & X & $\checkmark$ \\
X & $\checkmark$ & X & X & $\checkmark$ \\
X & $\checkmark$ & X & X & $\checkmark$ \\
$\checkmark$ & $\checkmark$ & X & X & $\checkmark$ \\
$\checkmark$ & $\checkmark$ & X & $\checkmark$ & $\checkmark$ \\
X & $\checkmark$ & X & X & $\checkmark$ \\
X & X & X & X & $\checkmark$ \\
$\checkmark$ & $\checkmark$ & X & $\checkmark$ & $\checkmark$ \\
$\checkmark$ & $\checkmark$ & X & $\checkmark$ & $\checkmark$ \\
$\checkmark$ & $\checkmark$ & $\checkmark$ & $\checkmark$ & $\checkmark$ \\
$\checkmark$ & $\checkmark$ & $\checkmark$ & $\checkmark$ & $\checkmark$
\end{tabular}

Remember to disinfect the container before using it to store clean water.
Do not use water with floating substances, bad odors or dark colors. Never drink floodwater.

Sources:

Centers for Disease Control and Prevention

United States Environmental Protection Agency

U.S. Department of Homeland Security - Federal Emergency Management Agency

UPR Recinto de Ciencias Médicas - Programa de Salud Ambiental

Oklahoma State University Food and Agricultural Products Research and Technology Center

The USDA Caribbean Climate Hub is located in San Juan, Puerto Rico and seeks to develop and provide scientific information, practical tools and greater capacity to the agricultural and forestry community of Puerto and the U.S. Virgin Islands to build resilience to climate change. We support the revival of agriculture and silviculture in Puerto Rico and the U.S. Virgin Islands after Hurricanes Irma and Maria. For more information visit:

Webpage: https://caribbeanclimatehub.org/; Facebook: https://www.facebook.com/CaribeHub/; Twitter: https://twitter.com/CaribeHub; YouTubehttp://www.youtube.com/c/CaribbeanClimateHub

Contact: William Gould, Hub Director, willlam.a.gould@usda.gov (787)-764-7790; Nora Álvarez-Berríos, Hub Climate Fellow, nora.l.alvarezberrios@usda.gov; (787) -764-7767 